\title{
Effects of Carbon Fiber Compression Ratio and Electrolyte Flow Rate on the Electrochemical Performance of Vanadium Redox Batteries
}

\author{
Zhongxu Tai, ${ }^{1}$ Kenzo Hanawa, ${ }^{2}$ Dongying Ju $\mathbb{D}^{1,2,3}$ Wenping Luo, ${ }^{1}$ Rui Lyu, ${ }^{2}$ \\ Kousuke Ishikawa, ${ }^{2}$ and Susumu Sato ${ }^{1}$ \\ ${ }^{1}$ Department of Information System, Saitama Institute of Technology, Fukaya, Japan \\ ${ }^{2}$ Tokyo Green Power Electric Research Institute Co. Ltd., Tokyo, Japan \\ ${ }^{3}$ Ningbo Haizhi Institute of Material Industry Innovation, Ningbo, China \\ Correspondence should be addressed to Dongying Ju; dyju@sit.ac.jp
}

Received 3 November 2020; Revised 1 February 2021; Accepted 1 March 2021; Published 11 March 2021

Academic Editor: Manuela Curcio

Copyright (C) 2021 Zhongxu Tai et al. This is an open access article distributed under the Creative Commons Attribution License, which permits unrestricted use, distribution, and reproduction in any medium, provided the original work is properly cited.

All-vanadium flow batteries (VRFBs) are used in the field of energy storage due to their long service life and high safety. In order to further improve the charge-discharge performance of VRFB, this study mainly used the comparative evaluation of VRFB's carbon fiber electrode compression ratio and electrolyte flow rate. The battery is charged and discharged under different current densities, different compression ratios, and different flow rates. The results show that increasing the compression ratio at different current densities can reduce the internal resistance of the battery, but an excessive compression ratio will accelerate the transfer of vanadium ions, increase the deviation of the electrolyte, and reduce the Coulombic efficiency of the battery. The performance of the battery tends to be balanced when the compression ratio is $30 \%$. At the same time, in the case of the same compression ratio, increasing the flow rate of the electrolyte can reduce the internal reaction resistance of the battery. When the flow reaches a certain value, the influence on the internal resistance will be smaller.

\section{Introduction}

The VRFB is a new type of energy storage battery that converts electrical energy into chemical energy during charging through the oxidation-reduction reaction of vanadium ions in different valence states and converts chemical energy into electrical energy during discharge (Figure 1) $[1,2]$. As early as the 1960 s, iron-chromium flow battery batteries have come out. The vanadium-based flow battery was successfully demonstrated for the first time by Maria Skyllas-Kazacos of the University of New South Wales in the 1980s [3,4]. After more than 30 years of continuous research and improvement, the vanadium flow battery technology has become increasingly mature. In China, Japan, and other countries, a number of all-vanadium flow batteries have been applied to the power grid as large-scale auxiliary power storage devices $[5,6]$.
The all-vanadium flow battery has many advantages, but its most important disadvantage is its low energy density $[7,8]$, which makes it large in size and expensive $[9,10]$. How to improve the charging and discharging performance of vanadium redox flow batteries and thus reduce the manufacturing cost of the batteries is the key to the research. It has become the main goal of vanadium flow battery research in recent years $[11,12]$. There are many factors that affect the charge and discharge performance of the vanadium redox flow battery, such as the design of the flow path, the concentration of the electrolyte, and the surface activity of the carbon fiber electrode $[13,14]$.

There are more and more research studies on improving the performance of vanadium flow batteries. Most of them are about two aspects of battery component materials and battery body frame optimization. In terms of materials, the major influences on battery performance are the carbon 


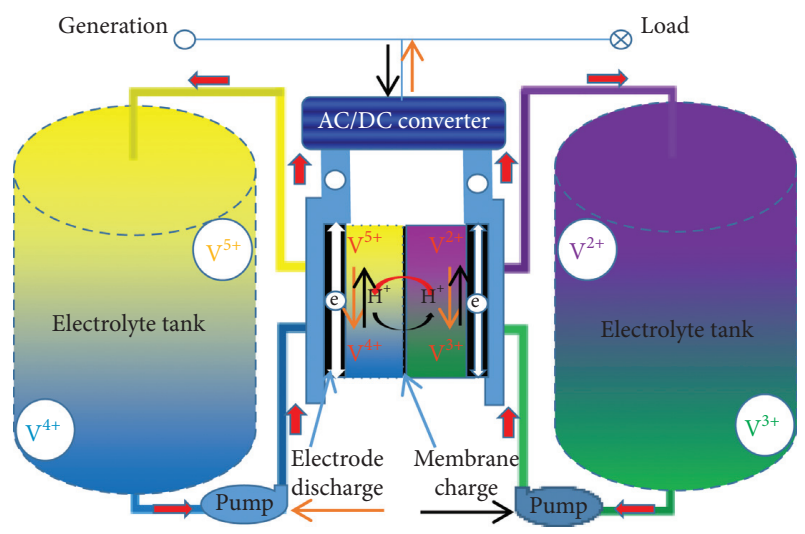

Figure 1: The VRFB charge and discharge principle diagram.

electrode and ion exchange membrane. As an important part of the battery, the research and development of higher performance electrode materials is the most enthusiastic direction of scientific researchers. In 2016, Hoyt et al. published a paper [15], which studied a copper plating process on the surface of a carbon electrode to make the battery current density reach $500 \mathrm{~mA} / \mathrm{cm}^{2}$. In the same year, Yarlagadda et al. published a paper [16], using constant current and pulse current electrodeposition techniques to deposit cobalt nanoparticles to catalyze the growth of multiwalled carbon nanotubes on the electrode surface, which greatly improved the battery performance. In 2018, Lu et al. published a paper [17]. The preparation of graphenecoated carbon by solution coating reduces the polarization of the battery. In 2020, Ye et al. published a paper [18] prepared SPEEK/GO/TiO2 composite film by the solution casting method for vanadium redox flow battery. Its excellent performance and low cost make it an ideal film for VRFB applications.

While battery materials continue to improve, the control of electrolyte flow/velocity is gradually being valued by researchers. In 2011, Doug Aaron of the University of Tennessee in the United States published a paper [19], studying the effect of flow velocity on battery current density. In 2012, Zhang of the Dalian Institute of Chemical Physics, Chinese Academy of Sciences, published a flow rate optimization strategy for vanadium flow batteries [20]. The experiment uses an $875 \mathrm{~cm}^{2} \times 15$ cell battery pack to determine the effect of different flow rates on the charge and discharge of the battery pack. Experiments show that both the battery capacity and the charging and discharging efficiency of the battery pack increase as the flow rate of the electrolyte increases, but the efficiency of the entire energy storage system decreases as the flow rate increases. In 2014, Tang and Skyllas-Kazacos of UNSW in Australia published a report on the influence of vanadium redox battery electrolyte flow rate on batteries and battery systems [21]. The results show that the auxiliary energy consumption is reduced at a low flow rate during the initial charge and discharge period. The flow rate in the later stage of discharge is increased to reduce the concentration point and improve the charge and discharge efficiency and battery power. In 2016, Kumar of IIT-Madras in India published a paper [22] on the influence of electrolyte flow rate on battery charge and discharge power density. The experimental results show that the battery voltage is affected by the concentration potential in the high current density area, and the maximum current density increases with the increase of the electrolyte flow rate. The maximum power density also increases with the increase of the electrolyte flow rate.

\section{Experimental Methods}

This experiment mainly studies the influence of the compression ratio and flow/velocity of carbon fiber on the charge and discharge performance of the vanadium redox flow battery under the same conditions. The experimental singlecell bipolar plate is $0.6 \mathrm{~mm}$, one kind of carbon fiber, the thickness is $4 \mathrm{~mm}$, and the area is $5 \mathrm{~cm} \times 10 \mathrm{~cm}=50 \mathrm{~cm}^{2}$. The experimental method is to determine the charge and discharge performance of the battery by changing the compression ratio of the carbon dioxide electrode and the flow rate of the electrolyte. According to the measured data, choose the most suitable plan.

2.1. Experimental Conditions. Due to the small electrode area of the vanadium redox battery on the market (about $4 \mathrm{~cm} \times 4 \mathrm{~cm}$ ), the electrolyte flow distance in the carbon fiber electrode is very short, and it is easy to achieve a uniform speed. The data obtained cannot fully explain the effect of electrolyte flow rate/flux on battery charging and discharging. Therefore, the battery used in this experiment is a self-designed single-cell battery with an electrode area of $50 \mathrm{~cm}^{2}(10 \mathrm{~cm} \times 5 \mathrm{~cm})$. The flow path is shown in Figure 2. The compression ratio of carbon fiber is controlled by changing the thickness of the body frame 2 . This experiment uses a variable flow screw pump, which tends to be more practical than a hose peristaltic pump. Peristaltic hose pumps are better in controlling flow and velocity, but large energy storage equipment cannot be used. Many experimental results obtained by using a hose peristaltic pump cannot be fully realized after the battery pack is expanded into a high-power variable-frequency pump. In this experiment, the battery diaphragm used proton exchange membrane (Nafion211), the bipolar plate was SGL $0.6 \mathrm{~mm}$ thick, and the collector plate was $0.6 \mathrm{~mm}$ thick gold-plated copper plate. The electrolyte is $1.6 \mathrm{~mol} / \mathrm{L}$ vanadium sulfate electrolyte manufactured by LE SYSTEM.

2.2. Calculation Method. Constant current ( $I=, 3 \mathrm{~A}, 4 \mathrm{~A}$, $5 \mathrm{~A})$ charging and discharging experiments are conducted on the assembled battery through a constant current output power supply. A constant current ( $I=3 \mathrm{~A}, 4 \mathrm{~A}, 5 \mathrm{~A})$ charge and discharge experiment $\left(C_{D}\right.$ current density: $60 \mathrm{~mA} / \mathrm{cm}^{2}$, $80 \mathrm{~mA} / \mathrm{cm}^{2}$, and $100 \mathrm{~mA} / \mathrm{cm}^{2}$ ) is performed on the assembled battery through a constant current output power supply. The charging and discharging voltage is $1.6 \mathrm{~V}-0.8 \mathrm{~V}$. The flow rate of the electrolyte is controlled by changing the voltage of the flow pump. Carbon fiber compression ratio $C_{R}$ calculation formula is shown in (1) (carbon fiber thickness: $d$; thickness after compression: $d_{0}$ ) 


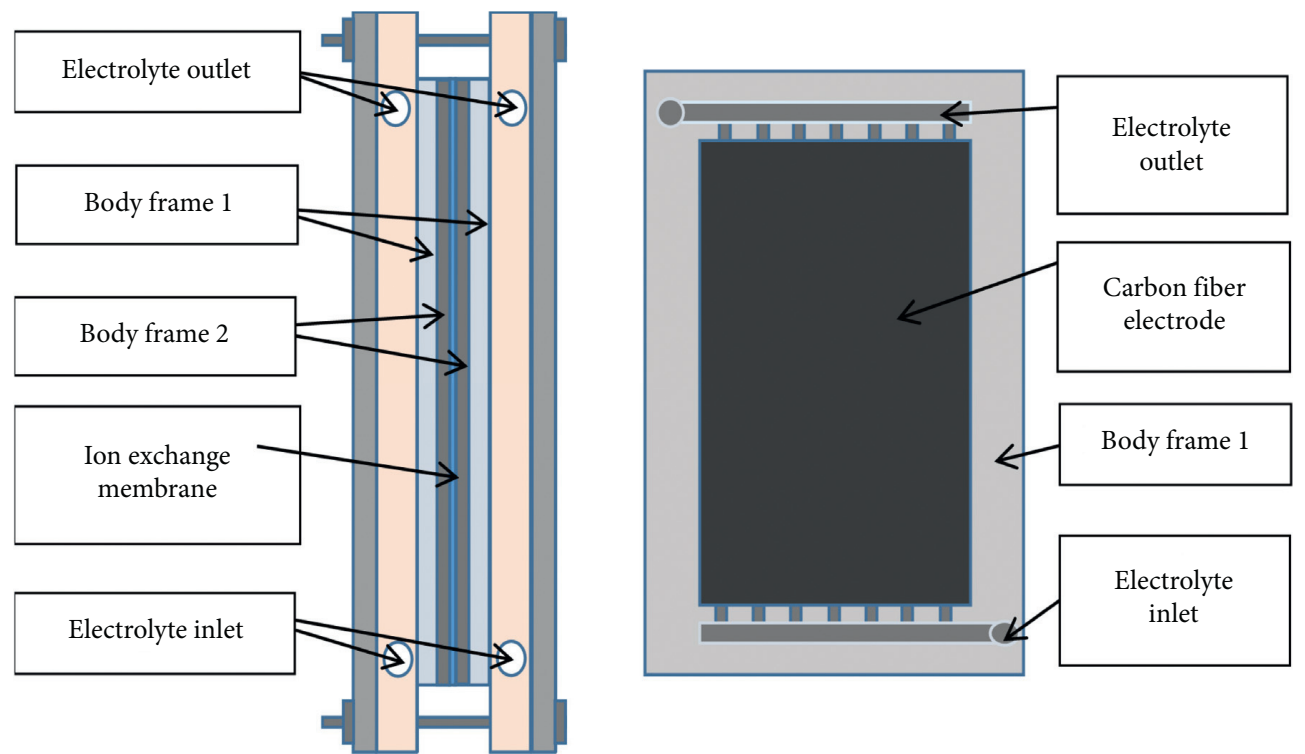

FIGURE 2: Self-made VRFB framework for experiment.

according to the constant current charge and discharge curve to calculate the battery's charge and discharge internal resistance $\left(I_{R}\right)$, voltage efficiency $\left(E_{V}\right)$, Coulomb efficiency $\left(E_{C}\right)$, energy efficiency $\left(E_{E}\right)$, energy density $\left(E_{D}\right)$, and output density $\left(O_{D}\right)$. The calculation formula is shown in (2)-(7) (pump voltage: $P_{V \text {. }}$, charge and discharge voltage: $U$, discharge time: $T_{d}$, and carbon fiber electrode volume: $\left.V_{1}\right)$. In addition, the flow and velocity of the electrolyte are measured by external measuring equipment:

$$
\begin{aligned}
C_{R} & =\frac{d-d_{0}}{d} \times 100 \%, \\
I_{R} & =\frac{U_{\text {avg.charge }}-U_{\text {avg.discharge }}}{2 C_{D}}, \\
E_{V} & =\frac{U_{\text {avg.discharge }}}{U_{\text {avg.charge }}} \times 100 \%, \\
E_{C} & =\frac{\int i_{\text {discharge }}(t) d t}{\int i_{\text {charge }}(t) d t} \times 100 \%, \\
E_{E} & =E_{V} \times E_{C}, \\
O_{D}(W / L) & =\frac{I \times U_{\text {avg.discharge }}}{V_{1}}, \\
E_{D}(\mathrm{Wh} / L) & =\frac{I \times T_{d} \times U_{\text {avg.discharge }}}{V_{1}} .
\end{aligned}
$$

\section{Experimental Results}

3.1. The Influence of Compression/Flow Ratio on the Internal Resistance of Battery Charge and Discharge. Figure 3 shows the different current density charge and discharge curves of the flow pump voltage of $2 \mathrm{~V}-5 \mathrm{~V}$ under different compression ratios. It can be seen from the comparison in Figure 3 that the charging and discharging curves appear to cross when the compression ratio increases. The initial charge voltage becomes lower, the initial discharge voltage becomes higher, and the charged battery OCV becomes larger. According to formula (2), the internal resistance $I_{R}$ of the battery can be calculated. The results are shown in Table 1.

According to the data in Table 1 , when the $C_{D}$ is the same, the battery's charge and discharge internal resistance IR decreases with the increase of $P_{V}$, and decreases with the increase of $C_{R}$. This is because the pore diameter of carbon is the same in the case of the same $C_{R}$, and the flow rate increases after flowing. The faster the flow rate of the electrolyte in the carbon pores, the faster the charge-discharge reaction, and the smaller the charge transfer resistance. In the case of the same $P_{V}$, increasing the compression ratio can effectively reduce the contact resistance between carbon, bipolar plate, and diaphragm whilst increasing the compression ratio and reducing the pore size of the carbon. Under the same pressure, the smaller the pores, the faster the electrolyte flow rate flowing through the surface of the carbon, the faster the charge and discharge reaction, and the smaller the charge transfer resistance.

Simultaneously, it can be seen from Figure 3 that under the same compression ratio, changing the supply flow rate of the electrolyte can effectively reduce the internal resistance of the battery during charge and discharge. The principle is the same as the previous explanation. When the flow rate of the pump reaches $4 \mathrm{~V}-5 \mathrm{~V}$, the charge and discharge curves of the battery tend to coincide. This shows that when the flow rate of the electrolyte reaches a certain level, it will no longer affect the internal resistance of the battery in charge and discharge. Figure 4 shows the relationship between pump input voltage and electrolyte flow rate under different compression ratios. It can be seen from the comparison in 


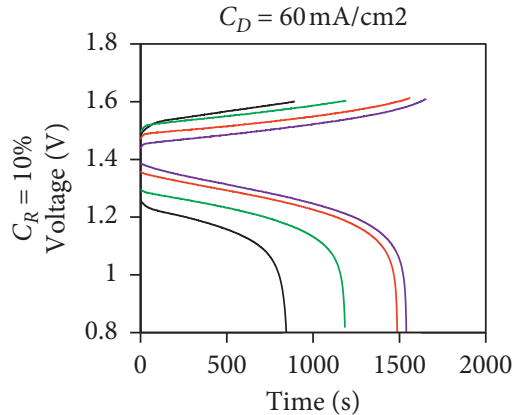

a1

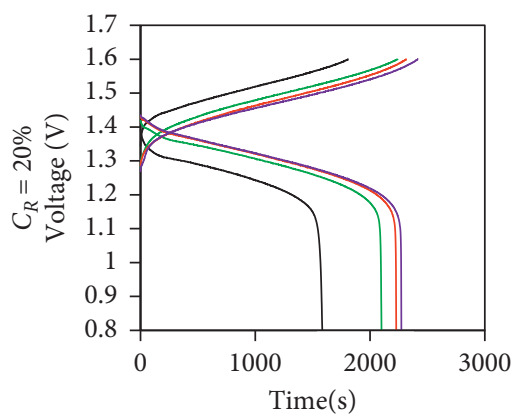

b1

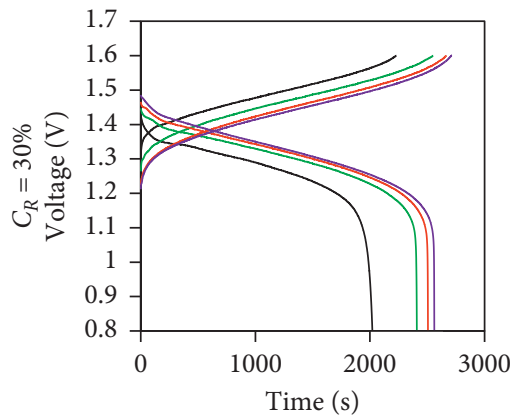

c1

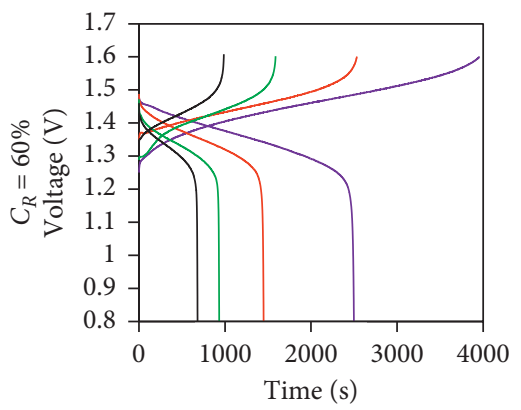

d1

- Pump voltage $2 \mathrm{~V}$

_ Pump voltage $3 \mathrm{~V}$

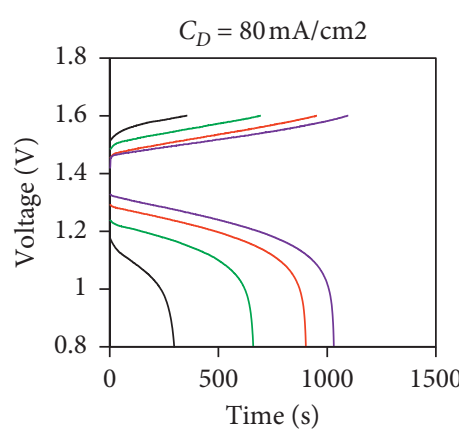

a2

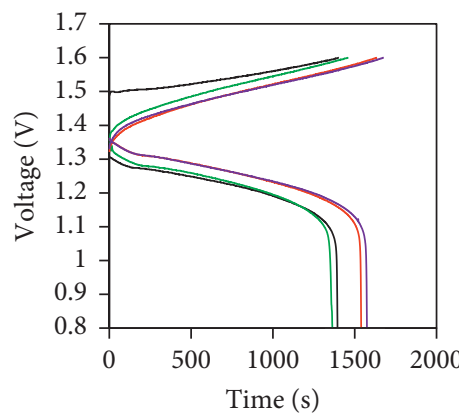

b2

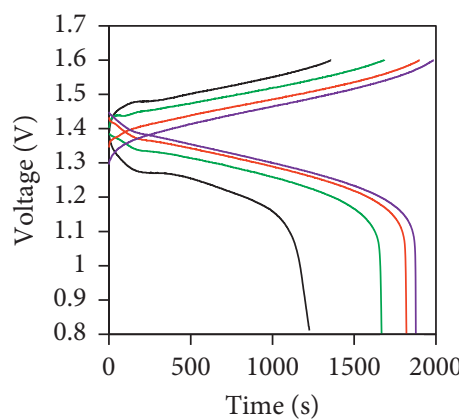

c2

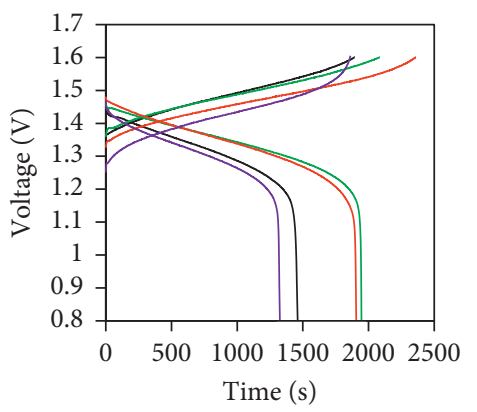

d2

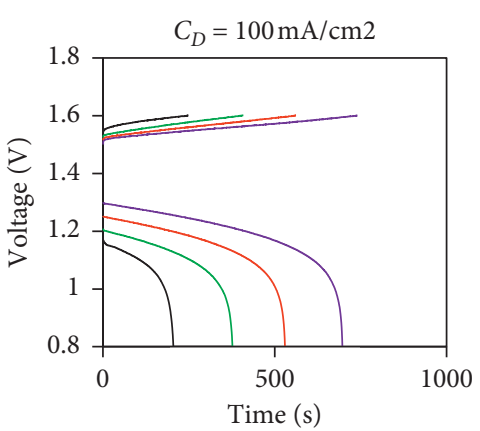

a3

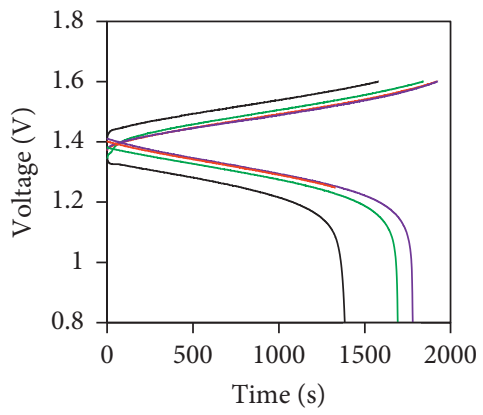

b3

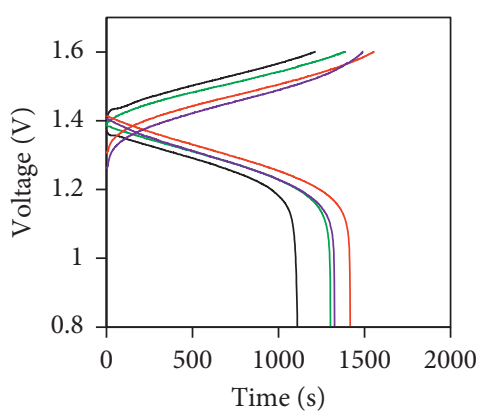

c3

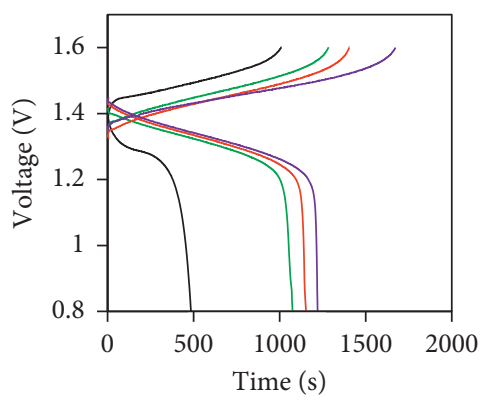

d3

Figure 3: Charge and discharge data with different current densities, different compression ratios, and different electrolyte flow rates.

the figure that the compression ratio increases and the flow rate of the electrolyte decreases.

\subsection{The Influence of Compression/Flow Ratio on Battery} Charge and Discharge Performance. According to the different constant current charging and discharging data and formula (2) to formula (7), the battery charging and discharging data can be calculated as shown in Table 2 . According to the data in Table 1, the relationship between the variable flow charging and discharging data under different compression ratios is summarized in Figure 5. As 
TABLE 1: $I_{R}$ changes under different $C_{R}$ and $P_{V}$.

\begin{tabular}{|c|c|c|c|c|c|}
\hline$C_{D}\left(\mathrm{~mA} / \mathrm{cm}^{2}\right)$ & $C_{R}(\%)$ & $P v=2 \mathrm{~V} I_{R}\left(\Omega / \mathrm{cm}^{2}\right)$ & $P v=3 \mathrm{~V} I_{R}\left(\Omega / \mathrm{cm}^{2}\right)$ & $P v=4 \mathrm{~V} I_{R}\left(\Omega / \mathrm{cm}^{2}\right)$ & $P v=5 \mathrm{~V} I_{R}\left(\Omega / \mathrm{cm}^{2}\right)$ \\
\hline \multirow{4}{*}{60} & 10 & 3.25 & 2.80 & 2.16 & 1.90 \\
\hline & 20 & 2.06 & 1.58 & 1.38 & 1.35 \\
\hline & 30 & 1.68 & 1.10 & 1.05 & 0.98 \\
\hline & 60 & 0.88 & 0.85 & 0.81 & 0.75 \\
\hline \multirow{4}{*}{80} & 10 & 3.26 & 2.48 & 2.03 & 1.79 \\
\hline & 20 & 1.91 & 1.72 & 1.52 & 1.51 \\
\hline & 30 & 1.80 & 1.41 & 1.13 & 0.99 \\
\hline & 60 & 1.01 & 0.92 & 0.76 & 0.70 \\
\hline \multirow{4}{*}{100} & 10 & 2.91 & 2.18 & 1.93 & 1.70 \\
\hline & 20 & 1.32 & 1.08 & 0.94 & 0.90 \\
\hline & 30 & 1.17 & 1.04 & 0.89 & 0.84 \\
\hline & 60 & 1.10 & 0.74 & 0.66 & 0.65 \\
\hline
\end{tabular}

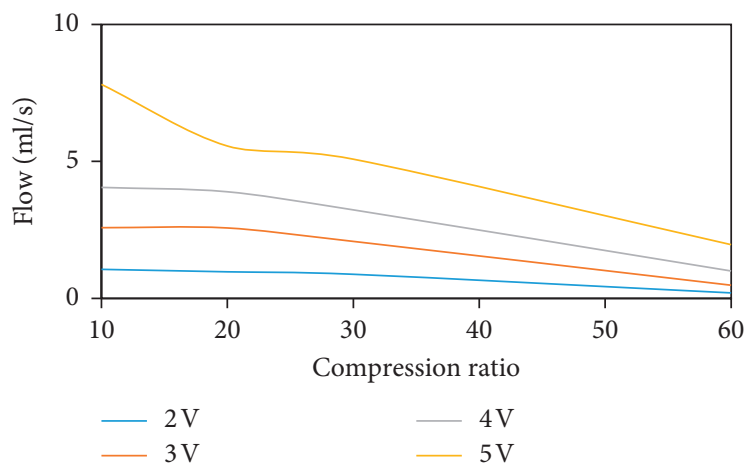

(a)

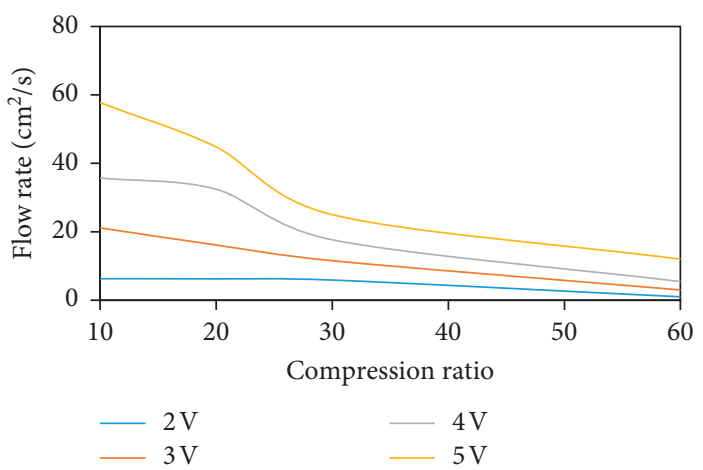

(b)

FIgURE 4: The relationship between pump input voltage and flow rate with different compression ratios of $4 \mathrm{~mm}$ carbon fiber.

TABLE 2: $4 \mathrm{~mm}$ carbon fiber charge and discharge settlement results with different compression ratios.

\begin{tabular}{|c|c|c|c|c|c|c|c|c|c|c|c|c|c|c|c|c|}
\hline \multirow[b]{2}{*}{$C_{R}(\%)$} & \multirow{2}{*}{$\begin{array}{l}C_{D} \\
P_{V} \\
(\mathrm{~V})\end{array}$} & \multicolumn{5}{|c|}{$60 \mathrm{~mA} / \mathrm{cm}^{2}$} & \multicolumn{5}{|c|}{$80 \mathrm{~mA} / \mathrm{cm} 2$} & \multicolumn{5}{|c|}{$100 \mathrm{~mA} / \mathrm{cm}^{2}$} \\
\hline & & $\begin{array}{l}E_{V} \\
(\%)\end{array}$ & $\begin{array}{c}E_{E} \\
(\%) \\
\end{array}$ & $\begin{array}{l}E_{C} \\
(\%) \\
\end{array}$ & $\begin{array}{c}O_{D} \\
(\mathrm{~W} / \mathrm{L}) \\
\end{array}$ & $\begin{array}{c}E_{D} \\
(\mathrm{Wh} / \mathrm{L})\end{array}$ & $\begin{array}{l}E_{V} \\
(\%) \\
\end{array}$ & $\begin{array}{l}E_{E} \\
(\%) \\
\end{array}$ & $\begin{array}{c}E_{C} \\
(\%) \\
\end{array}$ & $\begin{array}{c}O_{D} \\
(\mathrm{~W} / \mathrm{L}) \\
\end{array}$ & $\begin{array}{c}E_{D} \\
(\mathrm{Wh} / \mathrm{L})\end{array}$ & $\begin{array}{l}E_{V} \\
(\%) \\
\end{array}$ & $\begin{array}{l}E_{E} \\
(\%) \\
\end{array}$ & $\begin{array}{l}E_{C} \\
(\%) \\
\end{array}$ & $\begin{array}{c}O_{D} \\
(\mathrm{~W} / \mathrm{L}) \\
\end{array}$ & $\begin{array}{c}E_{D} \\
(\mathrm{Wh} / \mathrm{L})\end{array}$ \\
\hline \multirow{4}{*}{10} & 2 & 75.02 & 73 & 97.31 & 292.75 & 70.59 & 66.96 & 63.96 & 95.52 & 264 & 25.00 & 63.3 & 54.07 & 85.43 & 250.5 & 29.78 \\
\hline & 3 & 78.41 & 77.95 & 99.41 & 305 & 100.3 & 74.5 & 72.14 & 96.83 & 289.2 & 54.07 & 65.86 & 62.1 & 94.29 & 258.5 & 55.72 \\
\hline & 4 & 82.99 & 79.17 & 95.39 & 316 & 130.7 & 89.11 & 67.27 & 73 & 329 & 124.3 & 68.99 & 65.57 & 95.05 & 269.8 & 80.55 \\
\hline & 5 & 84.88 & 79.18 & 93.29 & 320 & 137.1 & 90.14 & 70.2 & 78.78 & 331.5 & 137.4 & 71.78 & 67.93 & 94.63 & 279.8 & 109.6 \\
\hline \multirow{4}{*}{20} & 2 & 83.6 & 74.73 & 89.36 & 315.8 & 142.1 & 91.74 & 85.34 & 94.68 & 336 & 184.2 & 82.63 & 74.79 & 90.51 & 314 & 124.82 \\
\hline & 3 & 87.24 & 83.47 & 95.68 & 325 & 193.7 & 92.16 & 74.85 & 81.57 & 335.8 & 179.5 & 86.11 & 80.5 & 93.49 & 322.5 & 154.26 \\
\hline & 4 & 88.75 & 86.76 & 97.76 & 327.5 & 206.2 & 88.26 & 85.26 & 96.24 & 325.5 & 162.5 & 87.38 & 81.74 & 93.55 & 325.5 & 162.48 \\
\hline & 5 & 89 & 84.29 & 94.71 & 327.5 & 208.5 & 89.13 & 86.12 & 95.13 & 326.5 & 163.2 & 87.89 & 82.09 & 93.41 & 326.5 & 163.16 \\
\hline \multirow{4}{*}{30} & 2 & 86.49 & 79.63 & 91.84 & 321.75 & 183.1 & 81.02 & 78.82 & 97.27 & 307.5 & 112.9 & 84.57 & 74.84 & 88.5 & 320.5 & 99.8 \\
\hline & 3 & 91.33 & 86.5 & 94.71 & 331.75 & 222.7 & 84.97 & 84.72 & 99.7 & 319.5 & 149.2 & 85.65 & 77.21 & 90.15 & 322.25 & 116.73 \\
\hline & 4 & 91.67 & 86.57 & 94.82 & 330.5 & 231 & 87.77 & 84.63 & 96.42 & 324.75 & 165.4 & 87.96 & 81.01 & 92.1 & 325 & 128.01 \\
\hline & 5 & 91.82 & 86.86 & 94.58 & 331.5 & 236.5 & 89.21 & 84.67 & 94.92 & 326.5 & 171.1 & 88.46 & 80.67 & 91.2 & 323 & 118.78 \\
\hline \multirow{4}{*}{60} & 2 & 92.86 & 53.56 & 57.4 & 331.8 & 64.23 & 89.11 & 67.27 & 73 & 329 & 124.2 & 85.27 & 43.27 & 50.74 & 318.5 & 45.39 \\
\hline & 3 & 93.67 & 65.57 & 70.62 & 333 & 89.17 & 90.14 & 70.2 & 78.78 & 331.5 & 137.4 & 89.9 & 75.69 & 84.19 & 329.5 & 98.94 \\
\hline & 4 & 93.3 & 59.62 & 64.25 & 337.8 & 136.4 & 91.74 & 85.34 & 94.68 & 336 & 184.2 & 90.92 & 77.26 & 84.98 & 330.25 & 109.53 \\
\hline & 5 & 92.81 & 56.86 & 60.71 & 338.8 & 239.2 & 92.16 & 74.85 & 81.57 & 335.7 & 179.5 & 90.5 & 67.74 & 74.85 & 331 & 115.21 \\
\hline
\end{tabular}

shown, the comparison between Table 2 and Figure 5 shows that when the $C_{R}$ is the same, the battery's charge and discharge performance $\left(E_{V}, E_{E}, O_{D}, E_{D}\right)$ increase with the increase of $P_{V}$. However, $E_{C}$ is maximum at $\mathrm{PV}=3 \mathrm{~V}-4 \mathrm{~V}$, the $P_{V}$ continues to increase, and $E_{C}$ decreases instead. This is because the diaphragm used this time is N211, the thickness of the diaphragm is thin, and the electrolyte offset is serious, which affects the Cullen efficiency of the battery. When $C_{R}=60 \% P_{V}=2 \mathrm{~V}$, the $E_{E}, E_{C}$, and $E_{D}$ of the battery are reduced by $50 \%$. It can be seen from Figure 4 that when 

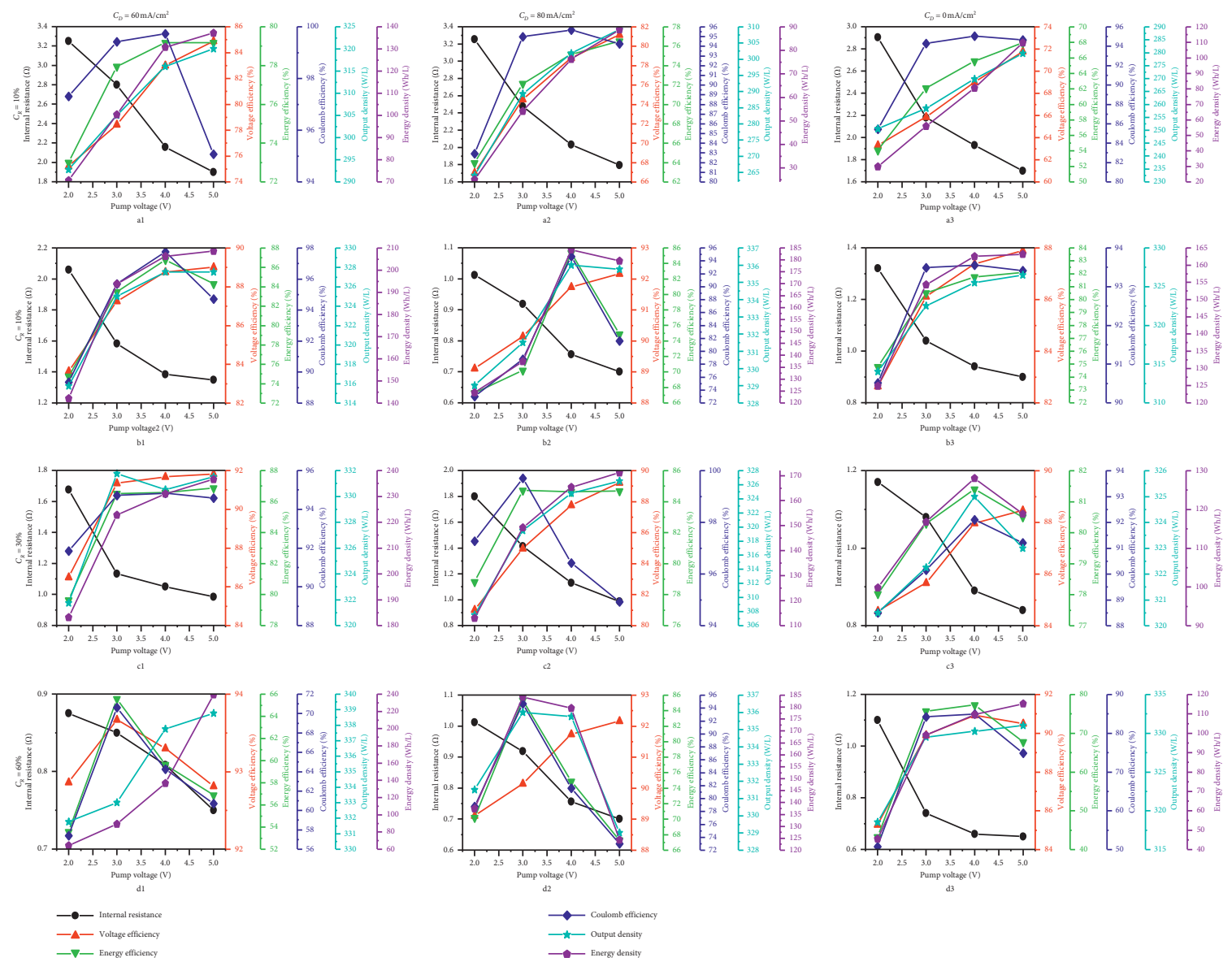

Figure 5: Comparison of battery charge and discharge performance at different flow rates at the same compression ratio.

$P_{V}=2 \mathrm{~V}$, the electrolyte flow rate is only $0.48 \mathrm{ml} / \mathrm{s}$. Because the electrolyte flow rate is too low, the reaction speed between the electrolyte and the carbon dioxide becomes low, and the voltage changes excessively during charge and discharge.

When the $P_{V}$ is the same, when the $C_{R}$ is below $60 \%, E_{V}$, $E_{E}, O_{D}$, and $E_{D}$ increase with the increase of $C_{R}$. $E_{C}$ decreases as $C_{R}$ increases. When $C_{R}$ is $60 \%$, the overall charge and discharge performance decreases. The overall performance is reduced by about $50 \%$. This is because carbon dioxide is overcompressed at $60 \%$, the specific surface area of the fiber is greatly reduced, the reaction speed of the electrolyte is reduced, and the charge and discharge performance is also reduced. Simultaneously, excessive compression makes the electrolyte drift more serious.

The long service life of the vanadium flow battery is its main feature. We conducted 50 repeated experiments on the battery under different current densities, different compression ratios, and different flow rates and calculated the changes in battery performance under different charge and discharge times. As the results of the first two charging and discharging experiments are unstable, the calculation results start from the third time. The experimental results are shown in Figure 6. $E_{C}$ increases with the increase in the number of charging and then tends to balance. $E_{V}$ and $E_{C}$ decrease as the number of charging increases. When $C_{R}=10 \% P_{V}=3 \mathrm{~V}$, the current density is $60 \mathrm{~mA} / \mathrm{cm}^{2}, E_{E}$ drops by $0.33 \%$ after 50 cycles of charge and discharge, and $E_{E}$ drops by $0.43 \%$. When the current density is increased by $100 \mathrm{~mA} / \mathrm{cm}^{2}, E_{E}$ decreases by $0.14 \%$, and $E_{V}$ decreases by $0.18 \%$. When $C_{R}=30 \% P_{V}=5 \mathrm{~V}$, the current density is $60 \mathrm{~mA} / \mathrm{cm}^{2}, E_{E}$ drops by $0.13 \%$ after 50 cycles of charge and discharge, and $E_{V}$ drops by $0.25 \%$. When the current density is increased by $100 \mathrm{~mA} / \mathrm{cm}^{2}$, the $E_{E}$ drops by $0.22 \%$ and the $E_{V}$ drops by $0.28 \%$. In summary, in the case of low compression ratio and low electrolyte flow, increasing the current density can reduce the degradation of the battery's charge and discharge performance. When the compression ratio and electrolyte flow are increased, the battery charge and discharge performance deteriorates seriously.

3.3. The Influence of Compression/Flow Ratio on Battery Charge and Discharge Performance. When the carbon fiber electrode is compressed, the fiber volume becomes smaller and the density becomes larger. The porosity and crosssectional area of the electrode flow direction decrease, and the flow velocity increases under the same flow rate. The 

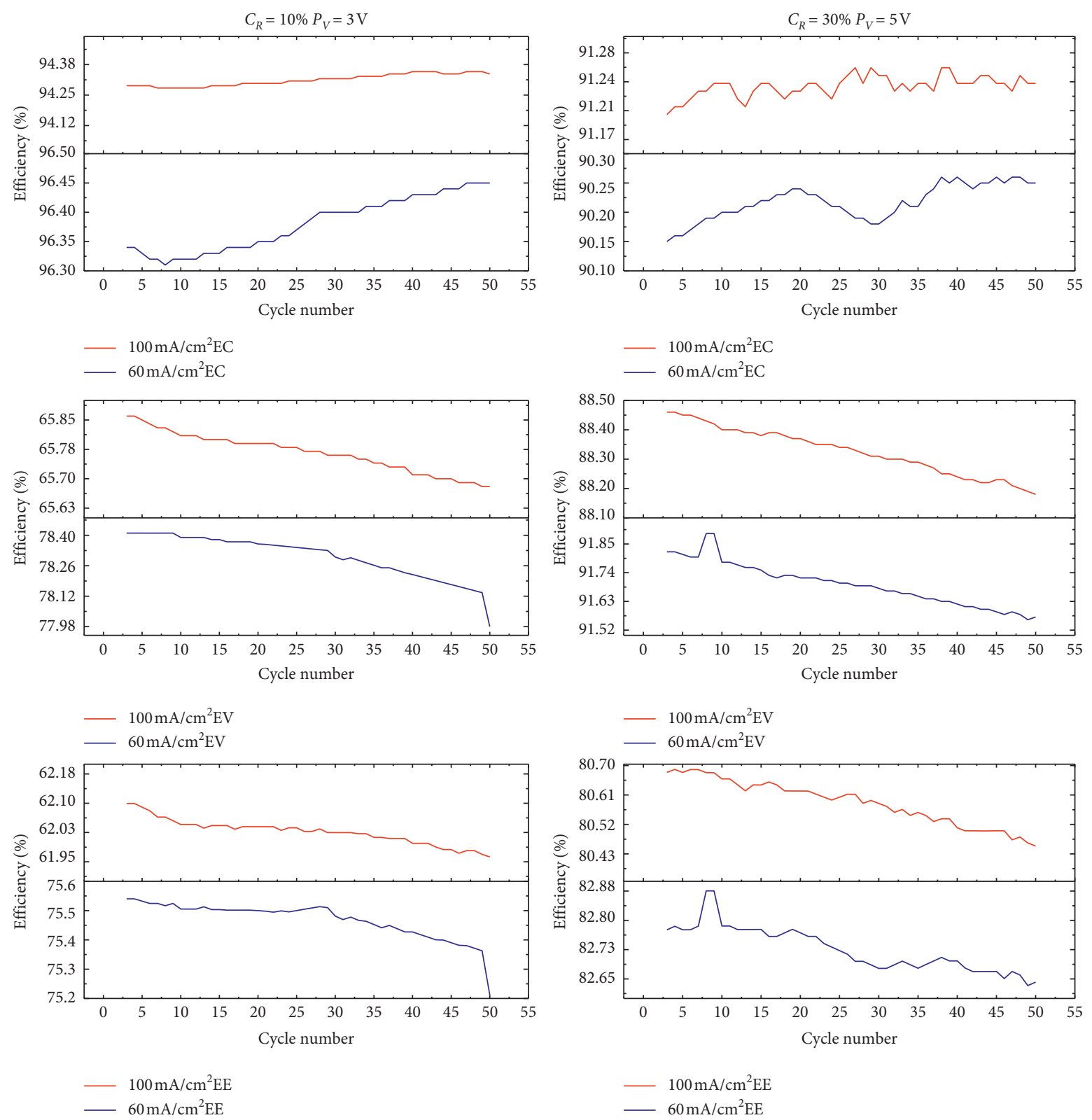

Figure 6: Current density of $60 \mathrm{~mA} / \mathrm{cm}^{2}$ and $100 \mathrm{~mA} / \mathrm{cm}^{2}$ and the changes of battery $E_{V}, E_{C}$, and $E_{E}$ under different $C_{R}$ and $P_{V}$ conditions.

increase in speed promotes the flow of the electrolyte, enhances the convection of the electrolyte on the surface of the carbon fiber electrode, and causes the concentration overpotential $\left(E_{c o n}\right)$ to decrease. The calculation formula of the concentration overpotential is shown in formulas (8)-(12) [23].

Where $R$ is the general gas constant $R, T$ is the experimental temperature, $F$ is the Faraday constant, $i$ is the charge and discharge current density, $i_{\text {lim }}$ is the limiting current density, $C$ is the volume concentration, $K$ is the mass transfer coefficient [24], and $V$ is the average velocity of the electrode solution. $Q$ is the flow rate of the electrolyte, $A_{f e l t}$ is the cross-sectional area, $\rho$ is the electrode porosity, $L_{\text {avg }}$ is the average length of the electrolyte flow path, $L_{f e l t}$ is the length of the carbon fiber electrode, and $\varepsilon$ is the porosity after compression [25]:

$$
\begin{aligned}
E_{\text {con }} & =\frac{\bar{R} T}{F} \ln \left(\frac{i_{\text {lim }}}{i_{\text {lim }}-i}\right), \\
i_{\text {lim }} & =F K C, \\
K & =1.6 \times 10^{-4} v^{0.4}, \\
v & =\frac{Q L_{\alpha v g}}{A_{\text {felt }} \varepsilon L_{\text {felt }}}, \\
\varepsilon & =\frac{\rho_{\text {fiber }}-\rho_{\text {felt }}}{\rho_{\text {fiber }}} .
\end{aligned}
$$

Formulas (8)-(10) calculate the concentration overpotential of the battery at different flow rates and different 
TABLE 3: The influence of compression ratio and flow rate on battery overpotential.

\begin{tabular}{|c|c|c|c|c|c|c|c|c|c|}
\hline$C_{R}(\%)$ & $P_{V}(V)$ & $\varepsilon$ & $L_{\alpha v \mathrm{~g}} / L_{\text {felt }}$ & $Q\left(m^{3} s^{-1}\right)$ & $V\left(m s^{-1}\right)$ & $K\left(m s^{-1}\right)$ & $i_{\lim }\left(A m^{-2}\right)$ & $E_{c o n}(m V)$ & $R_{\Omega}\left(\Omega \mathrm{cm}^{2}\right)$ \\
\hline \multirow{4}{*}{10} & 2 & 1.052 & 1.10 & $1.06 \times 10^{-7}$ & $6.15 \times 10^{-4}$ & $8.32 \times 10^{-6}$ & 1292 & 38.23 & 1.91 \\
\hline & 3 & 1.052 & 1.10 & $2.58 \times 10^{-7}$ & $1.50 \times 10^{-3}$ & $1.19 \times 10^{-5}$ & 1844 & 20.08 & 1.615 \\
\hline & 4 & 1.052 & 1.10 & $4.05 \times 10^{-7}$ & $2.35 \times 10^{-3}$ & $1.42 \times 10^{-5}$ & 2208 & 15.49 & 1.465 \\
\hline & 5 & 1.052 & 1.10 & $7.81 \times 10^{-7}$ & $4.54 \times 10^{-3}$ & $1.85 \times 10^{-5}$ & 2872 & 11.00 & 1.36 \\
\hline \multirow{4}{*}{20} & 2 & 0.976 & 1.08 & $0.97 \times 10^{-7}$ & $6.71 \times 10^{-4}$ & $8.61 \times 10^{-6}$ & 1337 & 35.42 & 1.32 \\
\hline & 3 & 0.976 & 1.08 & $2.57 \times 10^{-7}$ & $1.78 \times 10^{-3}$ & $1.27 \times 10^{-5}$ & 1974 & 18.15 & 1.08 \\
\hline & 4 & 0.976 & 1.08 & $3.89 \times 10^{-7}$ & $2.69 \times 10^{-3}$ & $1.50 \times 10^{-5}$ & 2330 & 14.41 & 0.94 \\
\hline & 5 & 0.976 & 1.08 & $5.56 \times 10^{-7}$ & $3.85 \times 10^{-3}$ & $1.73 \times 10^{-5}$ & 2688 & 11.95 & 0.9 \\
\hline \multirow{4}{*}{30} & 2 & 0.944 & 1.06 & $0.88 \times 10^{-7}$ & $7.06 \times 10^{-4}$ & $8.78 \times 10^{-6}$ & 1364 & 33.93 & 1.17 \\
\hline & 3 & 0.944 & 1.06 & $2.08 \times 10^{-7}$ & $1.67 \times 10^{-3}$ & $1.24 \times 10^{-5}$ & 1924 & 18.84 & 1.04 \\
\hline & 4 & 0.944 & 1.06 & $3.23 \times 10^{-7}$ & $2.59 \times 10^{-3}$ & $1.48 \times 10^{-5}$ & 2295 & 14.70 & 0.89 \\
\hline & 5 & 0.944 & 1.06 & $5.08 \times 10^{-7}$ & $4.07 \times 10^{-3}$ & $1.77 \times 10^{-5}$ & 2751 & 11.61 & 0.84 \\
\hline \multirow{4}{*}{60} & 2 & 0.794 & 1.02 & $0.20 \times 10^{-7}$ & $3.21 \times 10^{-4}$ & $6.41 \times 10^{-6}$ & 996 & - & 1.1 \\
\hline & 3 & 0.794 & 1.02 & $0.48 \times 10^{-7}$ & $7.70 \times 10^{-4}$ & $9.10 \times 10^{-6}$ & 1413 & 31.60 & 0.74 \\
\hline & 4 & 0.794 & 1.02 & $1 \times 10^{-7}$ & $1.60 \times 10^{-3}$ & $1.22 \times 10^{-5}$ & 1895 & 19.27 & 0.66 \\
\hline & 5 & 0.794 & 1.02 & $1.96 \times 10^{-7}$ & $3.14 \times 10^{-3}$ & $1.60 \times 10^{-5}$ & 2481 & 13.26 & 0.65 \\
\hline
\end{tabular}

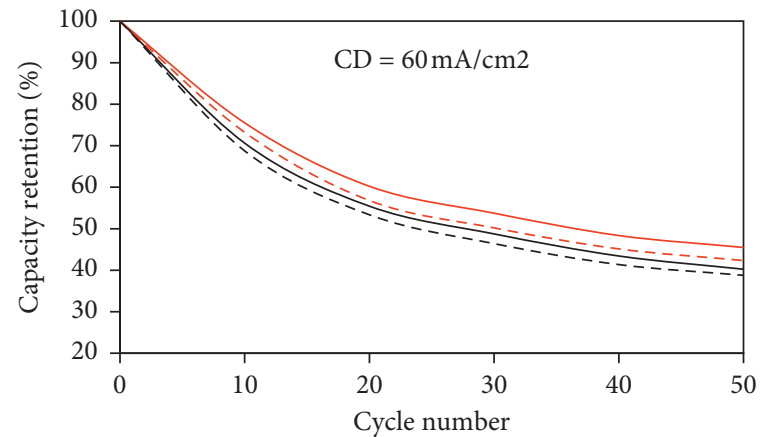

$\begin{array}{ll}3 \mathrm{~V} \mathrm{CR}=10 \% & -5 \mathrm{~V} \mathrm{CR}=10 \% \\ ---3 \mathrm{~V} \mathrm{CR}=30 \% & --5 \mathrm{~V} \mathrm{CR}=30 \%\end{array}$

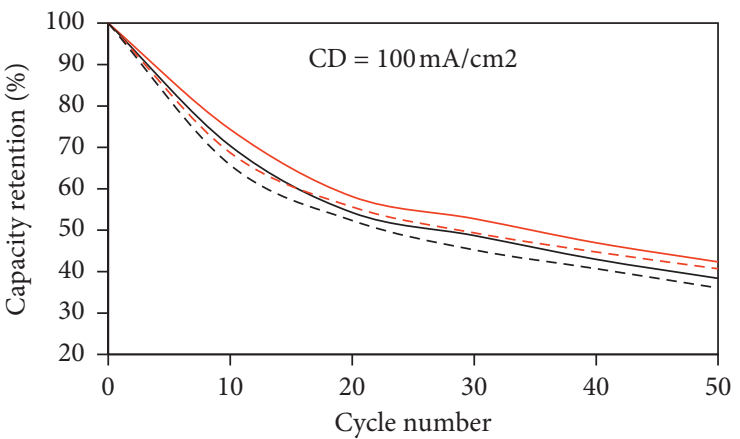

$\begin{array}{ll}3 \mathrm{~V} \mathrm{CR}=10 \% & -5 \mathrm{~V} \mathrm{CR}=10 \% \\ ---3 \mathrm{~V} \mathrm{CR}=30 \% & --5 \mathrm{~V} \mathrm{CR}=30 \%\end{array}$

Figure 7: The effect of compression ratio and flow rate on discharge capacity retention.

compression ratios. The calculation results are shown in Table 3. It can be seen from the data comparison that when the compression ratio is the same, increasing the flow rate can effectively reduce the concentration overpotential of the battery. The overpotential pair at $P_{V}=2 \mathrm{~V}$ and $P_{V}=5 \mathrm{~V}$ is reduced by $70 \%$.

However, when the flow rate is the same, the $C_{R}$ of the carbon fiber is increased. When the $C_{R}$ exceeds $30 \%$, the concentration overpotential of the battery increases instead. Therefore, an excessive compression ratio is not conducive to the concentration overpotential of the battery.

Through the data of 50 times of charge and discharge, we also compared the influence of battery discharge capacity under different conditions (as shown in Figure 7). The experimental results show that under the same compression ratio, increasing the flow rate of the electrolyte reduces the discharge capacity. At the same flow rate, increasing the compression ratio will also reduce the discharge capacity of the battery. Since the thickness of the N211 diaphragm is thinner and the permeability of vanadium ions is higher, increasing the flow rate promotes the transfer of vanadium ions, which lowers the discharge capacity. When the compression ratio is increased at the same time, the pressure between the electrolyte and the diaphragm increases, which further accelerates the penetration of vanadium ions.

\section{Conclusion}

Through the charge and discharge experiment of the battery under different compression ratios and different electrolyte flow rates, the following conclusions are obtained by comparing the experimental data:

(1) In the case of the same compression ratio, increasing the electrolyte flow rate can reduce the internal resistance of the battery during charge and discharge. When the flow rate reaches a certain value, the charge and discharge resistance does not change. In the case of the same electrolyte flow, slightly compressing the carbon fiber electrode can also reduce the charge and discharge resistance of the battery.

(2) In the case of the same compression ratio, increasing the electrolyte flow rate can improve the charge and discharge performance of the battery. When the flow 
rate reaches a certain value, the electrolyte offset will increase and the battery $E_{C}$ will decrease accordingly. Therefore, the thickness of the ion membrane should be selected according to the actual situation. In the case of the same electrolyte flow, slightly compressing the carbon fiber electrode can also improve the charge and discharge performance of the battery. However, when $C_{R}$ is too large, the performance of the battery will be offset.

(3) By comparing multiple charge and discharge data analysis, since this experiment uses N211 diaphragm, the permeability of vanadium ions is relatively high, so the compression rate and flow rate have a great influence on the battery discharge capacity. Therefore, choosing a separator with low vanadium ion permeability can increase the discharge capacity of the battery.

(4) In the case of the same compression ratio, increasing the flow rate of the electrolyte can effectively offset the concentration overpotential of the battery. In the case of the same electrolyte flow, the compression ratio is below $30 \%$, which can reduce the concentration overpotential of the battery, and excessive compression will increase the concentration overpotential of the battery.

\section{Nomenclature}
A: Area $\left(\mathrm{m}^{2}\right)$
C: Concentration $\left(\mathrm{molm}^{-3}\right)$
D: Density $(* / \mathrm{L})$
d: Discharge
E: Efficiency (\%)/energy
F: Faraday constant $\left(96485 \mathrm{Cmol}^{-1}\right)$
i: $\quad$ Current density $\left(\mathrm{Am}^{-2}\right)$
$\mathrm{K}$ : Mass transfer coefficient $\left(\mathrm{ms}^{-1}\right)$
L: Length $(\mathrm{m})$
O: Output density (W/L)
Q: Flow rate $\left(\mathrm{m}^{3} \mathrm{~s}^{-1}\right)$
$\bar{R}$ : Universal gas constant $\left(8.314 \mathrm{~kJ} \mathrm{~kg}^{-1} \mathrm{~K}^{-1}\right)$
R: Area specific resistance $\left(\Omega \mathrm{cm}^{2}\right)$
$\mathrm{t}$ : Thickness (m)
T: Temperature (K)/time (s)
$\mathrm{U}$ : Charge and discharge voltage $(\mathrm{V})$
v: Velocity $\left(\mathrm{ms}^{-1}\right)$
$\mathrm{V}$ : Cell voltage $(\mathrm{V})$
$V$ : Volume (L)
Greek Symbols
$\varepsilon$ : Porosity
$\rho:$ Density $\left(\mathrm{gcm}^{-3}\right)$
$\Omega:$ Ohm
Superscripts and Subscripts
avg: $\quad$ Average charge process
con: Concentration
discharge: Discharge process
felt: $\quad$ Felt
fiber: $\quad$ Fiber
lim: Limiting.

\section{Data Availability}

The data used to support the findings of this study are included within the article.

\section{Conflicts of Interest}

The authors declare that there are no conflicts of interest.

\section{Acknowledgments}

This research was based on the support of the New Multifunctional Secondary Battery Energy Storage Project of Ningbo Haizhi Material Industry Innovation Research Institute.

\section{References}

[1] H. Thallerl and A. W. Nice, "Fluid battery prom ises economical storage," Power Engineering, vol. 85, no. 2, pp. 56-58, 1981.

[2] L. H. Thaller, Electrically Rechangeable Redox Flow Cells, Vol. 924, SAE Prep rints,749142, San Francisco, USA, 1974.

[3] M. Skyllas-Kazacos and J. F. McCann, "Vanadium redox flow batteries (VRBs) for medium- and large-scale energy storage," Advances in Batteries for Medium and Large-Scale Energy Storage. Types and Applications Woodhead Publishing Series in Energy, pp. 329-386, 2015.

[4] N. P. H. Duraman, K. L. Lim, and S. L. I. Chan, "Batteries for remote area power (RAP) supply systems," Advances in Batteries for Medium and Large-Scale Energy Storage Types and Applications, Woodhead Publishing Seriesin Energy, pp. 563-586, 2015.

[5] S. Toshio, "Redox flow battery for energy storage," SEI technical review semanticscholar.org.Pages4-13, 2011.

[6] X. Liu and L. Kang, Energy Storage Devices in Electrified Railway Systems: A Review, Transportation Safety and Environment, tdaa016, 2020.

[7] Á. Cunha, J. Martins, N. Rodrigues, and F. P. Brito, "Vanadium redox flow batteries: a technology review," International Journal of Energy Research, vol. 39, no. 7.

[8] S. S. Hosseiny and M. Wessling, "Ion exchange membranes for vanadium redox flow batteries," Advanced Membrane Science and Technology for Sustainable Energy and Environmental Applications, 2011.

[9] R. Gundlapalli, "Sanjay kumar. Sreenivas jayanti. [Stack design considerations for vanadium redox flow battery]," INAE Letters, 2018

[10] Y. K. Zeng, T. S. Zhao, L. An, X. L. Zhou, and L. Wei, "A comparative study of all-vanadium and iron-chromium redox flow batteries for large-scale energy storage," Journal of Power Sources, vol. 300, no. 30, pp. 438-443, 2015.

[11] G. K. .A. A. Shah and F. C. Walsh, "Development of the allvanadium redox flow battery for energy storage: a review of technological, financial and policy aspects," International Journal of Energy Research, vol. 36, no. 11, 2011.

[12] C. Blanc and A. Rufer, "Understanding the vanadium redox flow batteries," Paths to Sustainable Energy, pp. 333-358, 2010

[13] Q. H. Liu, G. M. Grim, A. B. Papandrew, A. Turhan, T. A. Zawodzinski, and M. M. Mench, "High performance vanadium redox flow batteries with optimized electrode 
configuration and membrane selection," Journal of The Electrochemical Society, vol. 159, no. 8, 2012.

[14] M. R. Mohameda, P. K. Leungb, and M. H. Sulaimana, "Performance characterization of a vanadium redox flow battery at different operating parameters under a standardized test-bed system," Applied Energy, vol. 137, pp. 402-412, 2015.

[15] N. C. Hoyt and K. L. Hawthorne, R. F. Savinell and J. S. Savinell, "Plating utilization of carbon felt in a hybrid flow battery," Journal of The Electrochemical Society, vol. 163, no. 1, pp. A5041-A5048, 2016.

[16] V. Yarlagadda, G. Lin, P. Y. Chong, and T. Van Nguyen, "High surface area carbon electrodes for bromine reactions in H2-Br2Fuel cells," Journal of The Electrochemical Society, vol. 163, no. 1, pp. A5126-A5133, 2016.

[17] X. Lu, Q. Zhang, C. Wu et al., "Graphene coated carbon felt as a high-performance electrode for all vanadium redox flow batteries," Surface and Coatings TechnologyVolume, vol. 358, pp. 153-158, 2019.

[18] J. Ye, C. Wu, W. Qin, F. Zhong, and M. Ding, "Advanced sulfonated poly(ether ether ketone)/graphene-oxide/titanium dioxide nanoparticle composited membrane with superior cyclability for vanadium redox flow battery," Journal of Nanoscience and Nanotechnology, vol. 20, no. 8, pp. 47144721, 2020.

[19] D. Aaron, Z. Tang, A. B. Papandrew, T. A. Zawodzinski, and A. Thomas, "Polarization curve analysis of all-vanadium redox flow batteries," Journal of Applied Electrochemistry, vol. 41, no. 10, pp. 1175-1182, 2011.

[20] X. Ma, H. Zhang, C. Sun, and Y. Zou, "Tao Zhang[An optimal strategy of electrolyte flow rate for vanadium redox flow battery]," Journal of Power Sources, vol. 203, pp. 153-158, 2013.

[21] A. Tang, J. Bao, and M. Skyllas-Kazacos, "Studies on pressure losses and flow rate optimization in vanadium redox flow battery," Journal of Power Sources, vol. 248, p. 154, 2014.

[22] S. Kumar and S. Jayanti, "Effect of flow field on the performance of an all-vanadium redox flow battery," Journal of Power Sources, vol. 307, pp. 782-787, 2016.

[23] X. Ma, H. Zhang, and F. Xing, "A three-dimensional model for negative half cell of the vanadium redox flow battery," Electrochimica Acta, vol. 58, pp. 238-246, 2011.

[24] Y. Li, X. Zhang, J. Bao, M. Skyllas-Kazacos, X. Zhang, and J. Bao, "Control of electrolyte flow rate for the vanadium redox flow battery by gain scheduling," Journal of Energy Storage, vol. 14, no. 1, pp. 125-133, 2017.

[25] B. Dongjiang Youa, H. Zhanga, and J. Chena, "A simple model for the vanadium redox battery," Electrochimica Acta, vol. 54, pp. 6827-6836, 2009. 